\title{
2065 Prevalence and prognostic signficance of atherosclerotic disease of the aorta and its side branches in patients with chronic heart failure
}

\author{
Christos V Bourantas*1, Huan P Loh¹, Ramesh de Silva1, Klauss Witte1, \\ Elena I Lukaschuk ${ }^{1}$, Tony Nicoslon ${ }^{2}$, Simon Thackray ${ }^{1}$, Ann C Tweddel ${ }^{1}$, \\ Andrew L Clark ${ }^{1}$, Nikolay P Nikitin ${ }^{1}$ and John GF Cleland ${ }^{1}$
}

Address: ${ }^{1}$ Hull Univestity, Hull, UK and ${ }^{2}$ Leeds General Infirmary, Leeds, UK

* Corresponding author

from I th Annual SCMR Scientific Sessions

Los Angeles, CA, USA. I-3 February 2008

Published: 22 October 2008

Journal of Cardiovascular Magnetic Resonance 2008, I0(Suppl I):A334 doi:I0.I I86/I532-429X-I0-SI-A334

This abstract is available from: http://jcmr-online.com/content//0/SI/A334

(c) 2008 Bourantas et al; licensee BioMed Central Ltd.

\section{Introduction}

Aortic atherosclerosis and abdominal aortic aneurysms (AAA) are associated with adverse prognosis in general population. However, few data exist in patients with chronic heart failure (CHF).

\section{Purpose}

To investigate the prevelance and the prognostic significance of atherosclerosis of the aorta and its side branches in CHF patients.

\section{Methods}

Patients with CHF were referred routinely for cardiac magnetic resonance imaging (C-MRI) and gadolinium magnetic resonance aortography (Gd-MRA) as part of their standard assessment. Luminal stenoses of $>50 \%$ of the aorta and its branches and abdominal aortic aneurysms (AAA) were identified by two expert observers and termed atherosclerotic aortic disease (AAD).

\section{Results}

Of 203 patients investigated, 82 patients had no important aortic disease identified, 96 had a stenoses of $>50 \%$ of an aortic branch or distal aorta and 25 had an AAA. Patients with AAD were older $(p<0.0001)$, had more clinical evidence of fluid overload $(p=0.02)$, higher systolic blood pressure $(p=0.002)$ and higher pulse pressure $(p=$
0.003). Patients with AAD tended to spent more days to the hospital because of CHF $(1.9 \pm 7.9$ vs. $0.5 \pm 2.9$ days per patient per year; $\mathrm{p}=0.087$ ) and had longer hospital stays $(2.85 \pm 3.7$ vs. $0.5 \pm 2.9$ days per patient's hospitalisation per year; $\mathrm{p}=0.042$ ). Patients with AAD had a worse prognosis [hazard ratio (HR): $2.118 ; 95 \%$ confidence interval (CI): 1.041-4.309; $\mathrm{p}=0.038$. In a multi-variable model including 10 variables, ischemic heart disease (HR: 3.666; 95\% CI: 1.091-12.320; $\mathrm{p}=0.036$ ), b-blocker (HR: $0.394 ; 95 \%$ CI: $0.190-0.818 ; \mathrm{p}=0.012$ ) and the indexed by body surface area left ventricular end-diastolic volume (HR: 1.010 ; 95\% CI: 1.004-1.016; $\mathrm{p}=0.001$ ) were significantly related to outcome but not AAD. No death related to AAA was reported.

\section{Conclusion}

The prevalence of atherosclerotic disease of the aorta and its side branches is high in patients with CHF and, perhaps due to its association with other predictors of risk, associated with a worse prognosis. However, it is not yet clear whether or how AAD in should be managed in such patients to improve outcome. 